\title{
Communication in Individuals with Rett Syndrome: an Assessment of Forms and Functions
}

\author{
Robert Didden • Hubert Korzilius • Eric Smeets • \\ Vanessa A. Green • Russell Lang • \\ Giulio E. Lancioni • Leopold M. Curfs
}

Published online: 10 November 2009

(C) The Author(s) 2009. This article is published with open access at Springerlink.com

\begin{abstract}
In the present study we assessed the forms and functions of prelinguistic communicative behaviors for 120 children and adults with Rett syndrome using the Inventory of Potential Communicative Acts (IPCA) (Sigafoos et al. Communication Disorders Quarterly 21:77-86, 2000a). Informants completed the IPCA and the results were analysed to provide a systematic inventory and objective description of the communicative forms and functions present in each individual's repertoire. Results show that respondents reported a wide variety of communicative forms and functions. By far most girls used prelinguistic communicative behaviors of which eye contact/gazing was the most common form. The most often endorsed communicative functions were social convention, commenting, answering, requesting and choice-making. Problematic topographies (e.g., self-injury, screaming, non-
\end{abstract}

R. Didden $(\bowtie)$

Behavioural Science Institute, Radboud University Nijmegen, P.O. Box 9104, 6500 HE Nijmegen, The Netherlands

e-mail: r.didden@pwo.ru.nl

H. Korzilius

Institute for Management Research, Radboud University Nijmegen, Nijmegen, The Netherlands

E. Smeets $\cdot$ L. M. Curfs

University of Maastricht, Maastricht, The Netherlands

V. A. Green

Victoria University of Wellington, Wellington, New Zealand

R. Lang

The Eli and Edythe L. Broad Asperger Research Center, University of California, Santa Barbara, CA, USA

G. E. Lancioni

University of Bari, Bari, Italy 
compliance) were being used for communicative purposes in 10 to $41 \%$ of the sample. Exploratory analyses revealed that several communicative forms and functions were related to living environment, presence/absence of epilepsy, and age. That is, higher percentages of girls who showed some forms/functions were found in those who lived at home, who had no epilepsy and who were relatively young.

Keywords Rett syndrome $\cdot$ Children and adults $\cdot$ Prelinguistic behavior .

Communicative forms $\cdot$ Communicative functions $\cdot$ Communicative behaviors

Rett syndrome is a X-linked neurodevelopmental disorder affecting predominantly females in early childhood. The prevalence is estimated at 1.09 per 10,000 females by the age of 12 years (Laurvick et al. 2006). It is considered to be the second most common cause, after Down syndrome, of severe intellectual disability in females. In up to $90 \%$ of individuals with Rett syndrome, mutations in the MECP2 (methylcpG-binding protein 2) gene can be found (Smeets et al. 2003).

Rett syndrome is characterized by a progressive decline in motor and adaptive (i.e., cognitive, communicative) functioning starting when the child is between 5 and 18 months old. The condition results in profound cognitive impairment, stereotyped hand movements, breathing abnormalities (e.g., hyperventilation), seizures, scoliosis, and motor disorders (e.g., spasticity) as a result of which the child may require the use of a wheelchair (Matson et al. 2008b). The decline follows four stages: (a) stage 1: stagnation, (b) stage 2: regression, (c) stage 3: stationary, and (d) stage 4: motor deterioration (Budden et al. 1990; Lavas et al. 2006). Eventually, the child's behavioral repertoire and responsiveness to environmental stimulation is severely limited (Sigafoos et al. 2009).

Regression and severe deficits in communicative skills are one of the major criteria for Rett syndrome. Early studies (see Budden et al. 1990; Coleman et al. 1988) reported that young children with Rett syndrome often show a range of prelinguistic behaviors that may be used for communicative purposes, but that their speech and language development was restricted to only a few single words at most. Loss of speech and language abilities most often occurred after reaching stage 1, and some children showed some form of nonverbal prelinguistic communication at later stages.

Other researchers have provided a more detailed picture of communicative forms and functions in children with Rett syndrome. For example, Woodyatt and Ozanne (1992) assessed communicative behaviors in six girls (2-13 years old) with Rett syndrome. All children had lost the ability to communicate through speech after their initial regression and showed inconsistent social-communicative responses. Their expressive language skills were all assessed as being mainly at the preintentional level, but some communicative functions were inferred from the fact that some children engaged in various prelinguistic behaviors that appeared to serve a potential communicative function, including vocalizations, facial expressions, touching, and gazing. However, a confirmed communicative function could be identified in only two children who showed prelinguistic behaviors mainly for requesting objects and for gaining social interactions. All children showed limited imitation skills and older children did not show better communication skills than younger ones. 
These results suggest that some children with Rett syndrome may retain some communicative ability expressed through the use of prelinguistic behavior. If so, it would seem important to develop useful assessments to identify prelinguistic behaviors that the child may use for communication. Once identified, intervention could be targeted to strengthen the child's prelinguistic communication skills.

For the purpose of assessing the potential communicative forms and functions of existing prelinguistic behaviors in individuals with severe disabilities, Sigafoos et al. (2000a) developed the Inventory of Potential Communicative Acts (IPCA; see Method). Results of studies involving the IPCA have indicated that even when children present with extremely limited communicative and behavioral repertoires (e.g., eye gazing, body movements), they may nonetheless retain some prelinguistic acts that are interpreted by parents and teachers as communicative. Thus these retained prelinguistic acts could be seen as having some communicative functions.

The possible communicative functions that prelinguistic behaviors might serve for the child include (a) greeting, (b) conversation, (c) requesting an object, and (d) protesting and rejecting. However, these conclusions are based mainly on informantsupplied responses to the IPCA. Results from naturalistic observations to confirm these informant supplied responses remain inconclusive with respect to whether individuals' behaviors were in fact communicative (Dahlgren-Sandberg et al. 2000; Hetzroni and Rubin 2006). For example Dahlgren-Sandberg et al. assessed communicative functions in eight young women with Rett syndrome. Six of them showed some type of social interaction abilities while eye pointing was observed in only few individuals. Expressions of communicative intent (i.e. function) were rare. Also, Hetzroni and Rubin found that in eight girls with Rett syndrome (stage 4), eye gazing was the most common type of communicative behavior. As with the studies by Sigafoos et al. (2000a, b) and Dahlgren-Sandberg et al., the results of Hetzroni and Rubin suggest that is often difficult to assess the communicative function of prelinguistic behaviors in individuals with severe disabilities. However, it is unclear if this difficultly also extends to older individuals with Rett syndrome. One might suspect that over time, it may become easier to identify the communicative functions of a person's prelinguistic behaviors as these behaviors may become more situationally-specific over time and/or informants may improve in their ability to interpret the person's communicative intent over time.

There are several studies that have assessed communicative abilities in large samples of individuals with Rett syndrome and which have included both children and adults. For example, Cass et al. (2003) assessed communicative abilities in 87 children and adults with Rett syndrome who were referred to a tertiary multidisciplinary clinic. Two-thirds of the sample $(66 \%)$ used eye pointing for communicative purposes and about half (51\%) were able to make choices. Few $(7 \%)$ used words with any communicative intent. Analyses revealed that communication abilities were not related to age or to epilepsy and breathing difficulties, though there was a significant positive correlation between communication ability and mobility and self-help skills, and a negative correlation between communication ability and oral motor dysfunction.

Results from another study (Lavas et al. 2006), involving 125 children and adults (age range 2.5-55 years) with Rett syndrome, showed that most children (69\%) used one or more words during early childhood, but stopped speaking by 3 years. Forty 
individuals (32\%) used some type of communication aid (e.g., pictures, yes/no board). However, an interesting finding was that only $4 \%$ of them used graphical means to express their will. Most individuals (90\%) could express their will by eye pointing while half of the sample (55\%) used vocal means (e.g., sounds, laughter, screaming) for that purpose.

While the aforementioned studies have assessed communicative behaviors in individuals with Rett syndrome, several shortcomings should be mentioned: (a) sample size was small and selected (e.g., Dahlgren-Sandberg et al. 2000; Hetzroni and Rubin 2006), (b) detailed information on communicative form (e.g., Budden et al. 1990; Coleman et al. 1988) and communicative function (e.g., Lavas et al. 2006) was lacking, and/or (c) associations between communicative form/function and other variables, such as living circumstances were not explored (e.g., Lavas et al. 2006).

The aim of the present study was to (a) assess a comprehensive range of communicative forms and functions in a large sample $(n=120)$ of females with Rett syndrome, and (b) explore associations between form/function and other variables such as syndrome stage, presence of epilepsy/breathing difficulties, age and living setting. For this purpose, we used the Inventory of Potential Communicative Acts (see Method).

\section{Method}

\section{Participants and Setting}

The IPCA questionnaire (see below) was sent to 190 parents who were members of the Dutch Rett Syndrome Parent Association and who had a child with Rett syndrome. In an accompanying letter, parents were asked to complete the IPCA jointly. If their child lived in a residential facility, they were asked to complete the IPCA together with a staff member who knew the child well. Parents were sent a reminder after 5 weeks. We received 120 completed IPCAs, constituting a response rate of $63 \%$.

Participants were 120 females, and their mean age in years was $21.1(S D=11.97$; range: 5-55). Rett syndrome was confirmed (MECP2 mutation) in 89 (74\%) of the cases. Of the participants, $50 \%$ had classic or typical Rett syndrome, $24 \%$ had atypical Rett syndrome while syndrome type was unknown in $26 \%$ of the participants.

Most participants (65\%) lived at home with his or her parents, 35\% lived in a residential facility, and/or $8 \%$ lived in a community based group home. Of the sample, 72 females (60\%) had epilepsy, of which 29 (40\%) were seizure-free as a result of anticonvulsive medication. Most participants $(76 \%)$ had breathing difficulties/disturbances of whom 35 (38\%) showed shallow breathing, $29(32 \%)$ had hyperventilation, 70 (76\%) had breath holding spells, $30(33 \%)$ showed forced expulsion of air. Most participants (i.e., $n=90 ; 75 \%$ ) were wheelchair bound and scoliosis was present in 73 females $(61 \%)$.

\section{Inventory of Potential Communicative Acts}

The IPCA is a tool for the assessment of form and function of communicative behavior in people with severe communication impairments. It seeks to identify 
potential communicative acts or communicative forms that may be used by an individual for any of 10 communicative functions. A potential communicative act is defined as any behavior that the informant has identified as being used by the participant for communicative purposes (Sigafoos et al. 2000a, b). The IPCA is based on an extensive review of the literature and analyses of communicative forms and functions expressed by individuals with developmental disabilities and communication impairment (see e.g. Sigafoos et al. 2000a, b; Keen et al. 2002).

In the IPCA, ten categories of communicative function are delineated and accompanying questions are used to identify the forms of behavior that the child uses to accomplish each of these ten communication function. These categories (and example questions) are (a) social convention (e.g. 'How does your child greet you?'), (b) attention to self (e.g. 'How does your child request your attention?'), (c) reject/protest (e.g. 'What does your child do if a routine is disrupted?'), (d) request an object (e.g. 'How does your child let you know that s/he wants something?'), (e) request an action (e.g. 'How does your child let you know that s/he wants help with dressing?'), (f) request information (e.g. 'How does your child let you know that s/he needs clarification if s/he does not understand?'), (g) comment (e.g. 'How does your child let you know that s/he is happy?'), (h) choice making (e.g. 'How does your child choose between two objects?'), (i) answer (e.g., 'How does your child react when someone talks to him/her?'), and (j) imitation (e.g. 'How does your child imitate something that you say or do?').

The IPCA was developed through initial field testing with 30 children with developmental disabilities and severe communication impairments (Sigafoos et al. 2000a). The results of that field testing indicated that the IPCA was appropriate for gathering descriptive information on the existing pre-linguistic communicative behaviors of children with developmental disabilities and severe communication impairments (Sigafoos et al. 2000a, b). Field testing also indicated good agreement between parents and teacher informants, suggesting the IPCA has adequate interinformant agreement for the purpose of identifying the existing pre-linguistic communicative behaviors of children with developmental disabilities and severe communication impairments (Sigafoos et al. 2000a). The IPCA has also been shown to have adequate predictive validity for identifying intervention targets in programs aimed at replacing pre-linguistic communication acts with more formal communication skills (Keen et al. 2002; Tait et al. 2004).

The IPCA was translated into Dutch and completed by parents and caretakers who knew the participant for at least 6 months. For the purpose of this study, several additional questions were added (e.g., type and stage of Rett syndrome, age, epilepsy, breathing difficulties, scoliosis, and living setting). Parent and caregiver informants were asked to describe the communicative behaviors (i.e. forms) that $\mathrm{s} / \mathrm{he}$ had observed in the individual with Rett syndrome for each of the above ten categories. In the IPCA, a wide variety of examples of communicative behaviors or forms are given as examples from which the informant may choose. These are nonsymbolic (e.g., eye gazing, pointing, facial expressions, bodily movements, vocalizations, challenging behavior) and symbolic communicative behaviors (e.g., use of pictures, and pointing to a picture on a communication board). Informants were encouraged to mention other communicative behaviors that were not included in the list of examples of communicative acts. 
Statistical Analyses

Each returned IPCA was summarized and entered into tables for analysis. The first analysis was percentage of individuals with Rett syndrome who showed each communicative form for each of the ten communicative functions. This was calculated for the overall sample based on the communicative behaviors that were mentioned by respondents. Following this, comparisons were made of the percentage of individuals that showed each communicative form and function by syndrome stage, presence of epilepsy/breathing difficulties, age, and living environment. These comparisons were made using chi-square analyses.

\section{Results}

Percentages of females with Rett syndrome who showed communicative forms for each of the ten communicative functions are shown in Table 1. Most of the communicative behaviors are pre-linguistic or non-symbolic. A variety of communicative forms were used of which the most common types were eye contact/gazing and laughing/smiling. Only 15 to $16 \%$ of the females used some type of symbolic communication (i.e. speech/words) for the purpose of requesting. In our sample, other symbolic communication forms, such as manual signs or voice output devices, were not mentioned by respondents. The most often endorsed communicative functions were social convention, commenting, answering, requesting and choicemaking. Problematic topographies (e.g., self-injury, screaming, non-compliance) were being used for communicative purposes in 10 to $41 \%$ of the sample. Such topographies were mainly used for the purpose of commenting, and requesting an object, attention and/or action. Finally, only a small number of females (13\%) showed stereotyped hand movements and this behavior was shown for the purpose of commenting.

Tables 2, 3 and 4 show percentages of females with Rett syndrome that showed communicative forms and functions as related to other variables. Outcomes were compared for females living at home and those living in a residential facility (Table 2), females with and without epilepsy (Table 3), and females in different age groups (Table 4).

Results in Table 2 show that there were significant differences between females with Rett syndrome who lived at home and those living in a facility in 'eye contact/ gaze' for the purpose of rejecting and protesting and requesting an object. Other significant differences were for 'laughing/smiling' (for choice-making and answering), and 'vocalizations' (for request an action). In general, several communicative forms and functions were most often found in females who lived at home than in those living in a facility except for 'closing eyes' which was more often found in females living in a facility.

The presence or absence of epilepsy was related to communicative forms in that more females without epilepsy used 'approaching of another person' for the purposes of social convention and drawing attention to oneself than females with epilepsy. Females without epilepsy for example were more often 'looking happy' for the purpose of answering than those with epilepsy. Generally, communicative forms 


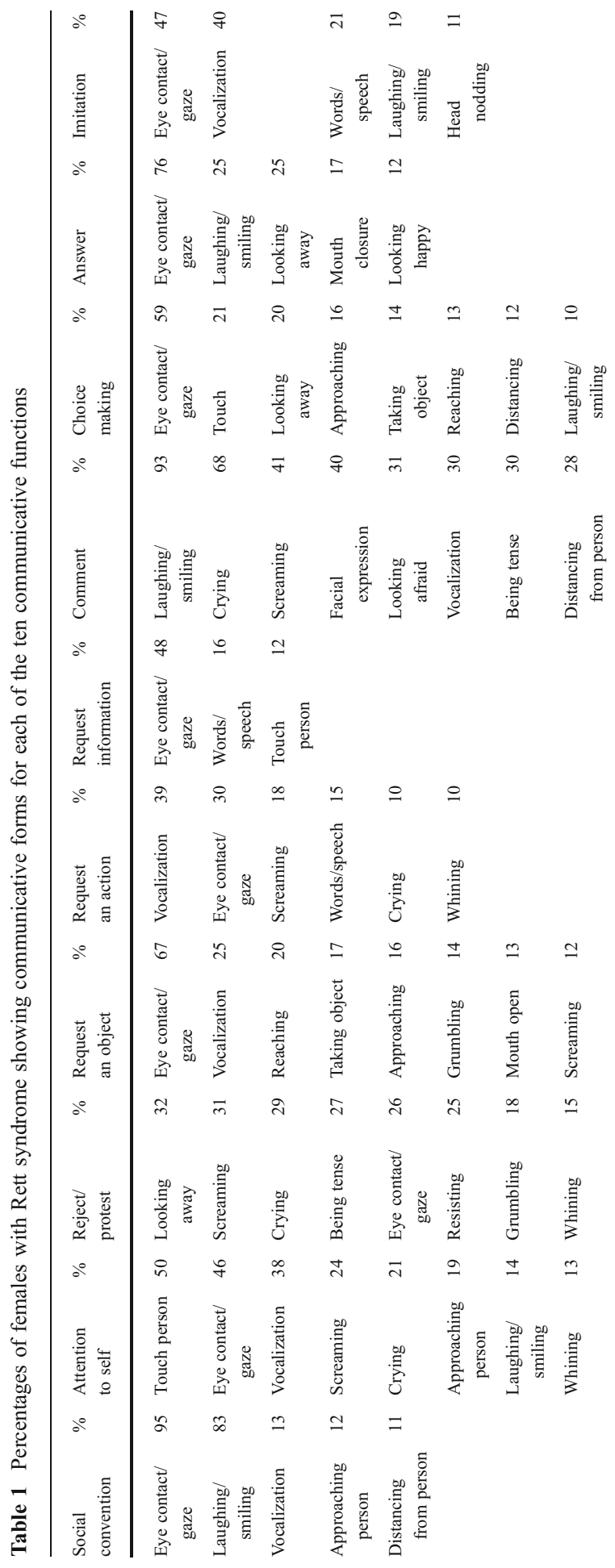




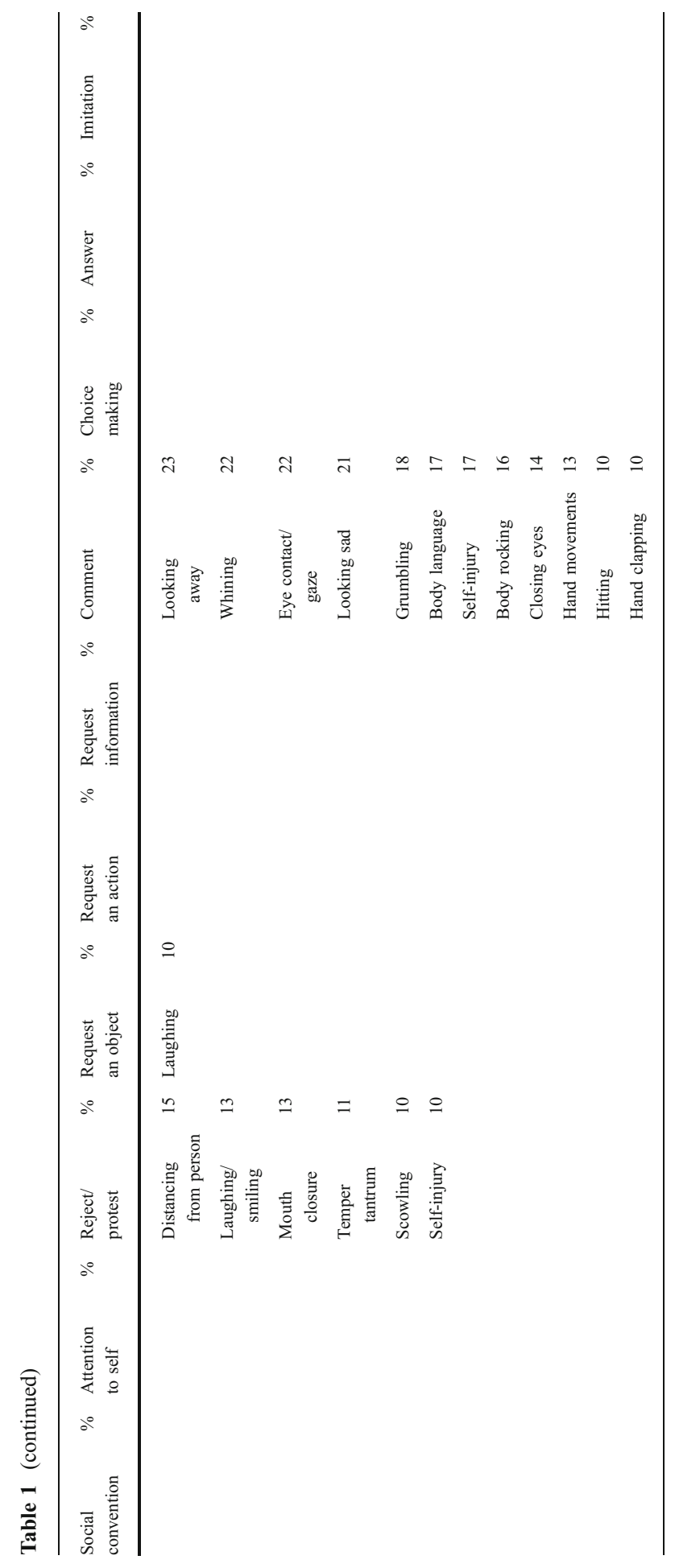


Table 2 Percentage of females with Rett syndrome who are living at home and in a residential facility and who show functions and forms of communicative behaviors, chi-square and p-values

\begin{tabular}{|c|c|c|c|c|}
\hline Function/form & Home $(n=68) \%$ & Residential $(n=53) \%$ & $\chi^{2}(d f=1)$ & $p$ \\
\hline \multicolumn{5}{|l|}{ Social convention } \\
\hline Eye contact/gaze & 97 & 91 & $-{ }^{\mathrm{a}}$ & .24 \\
\hline Laughing/smiling & 82 & 83 & 0.01 & .92 \\
\hline Approaching person & 12 & 11 & 0.01 & .94 \\
\hline Distancing from person & 10 & 11 & 0.03 & .86 \\
\hline \multicolumn{5}{|l|}{ Attention to self } \\
\hline Touch person & 54 & 38 & 3.32 & .07 \\
\hline Approaching person & 24 & 11 & 2.98 & .08 \\
\hline \multicolumn{5}{|l|}{ Reject/protest } \\
\hline Eye contact/gaze & 35 & 9 & 10.93 & $.00 * *$ \\
\hline Resisting & 21 & 26 & 0.57 & .45 \\
\hline Grumbling & 19 & 13 & 0.75 & .39 \\
\hline Temper tantrum & 10 & 9 & 0.03 & .88 \\
\hline \multicolumn{5}{|l|}{ Request an object } \\
\hline Eye contact/gaze & 65 & 45 & 4.57 & $.03 *$ \\
\hline Reaching & 22 & 9 & 3.44 & .06 \\
\hline Taking object & 18 & 9 & 1.66 & .20 \\
\hline Approaching person & 21 & 4 & 7.34 & $.01 *$ \\
\hline \multicolumn{5}{|l|}{ Request an action } \\
\hline Vocalizing & 32 & 13 & 5.99 & $.01 *$ \\
\hline Words/speech & 13 & 4 & 3.23 & .07 \\
\hline \multicolumn{5}{|l|}{ Request information } \\
\hline Eye contact/gaze & 12 & 8 & 0.59 & .44 \\
\hline Touch person & 3 & 2 & $--^{\mathrm{a}}$ & 1.00 \\
\hline \multicolumn{5}{|l|}{ Comment } \\
\hline Looking away & 21 & 38 & 4.34 & $.04 *$ \\
\hline Whining & 30 & 13 & 4.51 & $.03 *$ \\
\hline Closing eyes & 7 & 23 & 5.77 & $.02 *$ \\
\hline Hitting & 12 & 8 & 0.59 & .44 \\
\hline \multicolumn{5}{|l|}{ Choice making } \\
\hline Eye contact/gaze & 52 & 36 & 2.94 & .09 \\
\hline Approaching person & 18 & 6 & 3.94 & $.05^{*}$ \\
\hline Reaching & 15 & 4 & 3.99 & $.05^{*}$ \\
\hline Distancing from person & 13 & 4 & 3.23 & .07 \\
\hline \multicolumn{5}{|l|}{ Answer } \\
\hline Laughing/smiling & 60 & 40 & 5.10 & $.02 *$ \\
\hline Mouth closure & 18 & 15 & 0.14 & .71 \\
\hline Looking happy & 12 & 11 & 0.01 & .94 \\
\hline \multicolumn{5}{|l|}{ Imitation } \\
\hline Eye contact/gaze & 22 & 23 & 0.01 & .94 \\
\hline Words/speech & 12 & 8 & 0.59 & .44 \\
\hline
\end{tabular}

${ }^{\text {a }}$ As a result of low cell frequencies no chi-square value can be calculated. Fisher's exact test $p$-value is given

$* p<.05 ; * * p<.01$ 
Table 3 Percentage of females with Rett syndrome with and without epilepsy who show forms and functions of communicative behavior, chi-square and p-values

\begin{tabular}{|c|c|c|c|c|}
\hline Function/form & No epilepsy $(n=41) \%$ & Epilepsy $(n=72) \%$ & $\chi^{2}(d f=1)$ & $p$ \\
\hline \multicolumn{5}{|l|}{ Social convention } \\
\hline Eye contact/gaze & 95 & 96 & $--^{\mathrm{a}}$ & 1.00 \\
\hline Laughing/smiling & 78 & 88 & 1.74 & .19 \\
\hline Approaching person & 20 & 6 & 5.36 & $.02 *$ \\
\hline Distancing from person & 12 & 8 & 0.44 & .51 \\
\hline \multicolumn{5}{|l|}{ Attention to self } \\
\hline Touch person & 56 & 40 & 2.63 & .11 \\
\hline Approaching person & 32 & 10 & 8.67 & $.00^{* *}$ \\
\hline \multicolumn{5}{|l|}{ Reject/protest } \\
\hline Eye contact/gaze & 27 & 22 & 0.31 & .58 \\
\hline Resisting & 37 & 18 & 4.81 & $.03 *$ \\
\hline Grumbling & 27 & 11 & 4.61 & $.03 *$ \\
\hline Temper tantrum & 12 & 8 & 0.44 & .51 \\
\hline \multicolumn{5}{|l|}{ Request an object } \\
\hline Eye contact/gaze & 63 & 53 & 1.20 & .27 \\
\hline Reaching & 12 & 18 & 0.67 & .41 \\
\hline Taking object & 24 & 7 & 6.91 & $.01 *$ \\
\hline Approaching person & 17 & 8 & 1.96 & .16 \\
\hline \multicolumn{5}{|l|}{ Request an action } \\
\hline Vocalization & 29 & 19 & 1.42 & .23 \\
\hline Words/speech & 15 & 6 & 2.67 & .10 \\
\hline \multicolumn{5}{|l|}{ Request information } \\
\hline Eye contact/gaze & 5 & 11 & 1.26 & .26 \\
\hline Touch person & 2 & 1 & $-{ }^{\mathrm{a}}$ & 1.00 \\
\hline \multicolumn{5}{|l|}{ Commenting } \\
\hline Looking away & 24 & 32 & 0.72 & .40 \\
\hline Whining & 22 & 22 & 0.00 & .97 \\
\hline Eyes closing & 10 & 18 & 1.41 & .24 \\
\hline Hitting & 15 & 8 & 1.09 & .30 \\
\hline \multicolumn{5}{|l|}{ Choice making } \\
\hline Eye contact/gaze & 44 & 44 & 0.00 & .96 \\
\hline Approaching person & 15 & 10 & 0.62 & .43 \\
\hline Reaching & 7 & 7 & 0.01 & .94 \\
\hline Distancing from person & 17 & 3 & 7.28 & $.01 *$ \\
\hline \multicolumn{5}{|l|}{ Answer } \\
\hline Laughing/smiling & 61 & 46 & 2.40 & .12 \\
\hline Mouth closure & 17 & 17 & 0.00 & .96 \\
\hline Looking happy & 24 & 6 & 8.54 & $.00 * *$ \\
\hline \multicolumn{5}{|l|}{ Imitation } \\
\hline Eye contact/gaze & 34 & 17 & 4.51 & $.03 *$ \\
\hline Words/speech & 17 & 7 & 2.82 & .09 \\
\hline
\end{tabular}

${ }^{a}$ As a result of low cell frequencies no chi-square value can be calculated. Fisher's exact test $p$-value is given

$* p<.05 ; * * p<.01$ 
Table 4 Percentage of children (4-12 years), youth (13-21 years) and adults (22-54 years)with Rett syndrome who show functions and forms of communicative behaviors, chi-square and p-values

\begin{tabular}{|c|c|c|c|c|c|}
\hline Function/form & Children $(n=41) \%$ & Youth $(n=30) \%$ & Adults $(n=50) \%$ & $\chi^{2}(d f=1)$ & $p$ \\
\hline \multicolumn{6}{|l|}{ Social convention } \\
\hline Eye contact/gaze & 98 & 93 & 92 & $-^{\mathrm{a}}$ & .61 \\
\hline Laughing/smiling & 78 & 87 & 84 & 1.01 & .61 \\
\hline Approaching person & 17 & 10 & 8 & $-^{\mathrm{a}}$ & .39 \\
\hline Distancing from person & 15 & 10 & 8 & $-^{\mathrm{a}}$ & .57 \\
\hline \multicolumn{6}{|l|}{ Attention to self } \\
\hline Touch person & 63 & 50 & 32 & 9.06 & $.01 *$ \\
\hline Approaching person & 32 & 17 & 8 & 8.57 & $.01 *$ \\
\hline \multicolumn{6}{|l|}{ Reject/protest } \\
\hline Eye contact/gaze & 32 & 43 & 6 & 16.38 & $.01 *$ \\
\hline Resisting & 22 & 37 & 16 & 4.55 & .10 \\
\hline Grumbling & 24 & 30 & 2 & 13.43 & $.01^{*}$ \\
\hline Temper tantrum & 10 & 7 & 12 & $-{ }^{\mathrm{a}}$ & .87 \\
\hline \multicolumn{6}{|l|}{ Request an object } \\
\hline Eye contact/gaze & 76 & 63 & 36 & 15.18 & $.00 * *$ \\
\hline Reaching & 37 & 0 & 10 & 19.44 & $.00 * *$ \\
\hline Taking object & 24 & 17 & 4 & 7.98 & $.02 *$ \\
\hline Approaching person & 29 & 7 & 4 & 14.03 & $.00 * *$ \\
\hline \multicolumn{6}{|l|}{ Request action } \\
\hline Vocalization & 37 & 37 & 6 & 15.10 & $.00^{*}$ \\
\hline Words/speech & 12 & 13 & 4 & $--^{\mathrm{a}}$ & .22 \\
\hline \multicolumn{6}{|l|}{ Request information } \\
\hline Eye contact/gaze & 7 & 27 & 2 & $-^{\mathrm{a}}$ & $.00 * *$ \\
\hline Tocuh person & 2 & 7 & 0 & $-^{\mathrm{a}}$ & .11 \\
\hline \multicolumn{6}{|l|}{ Commenting } \\
\hline Looking away & 20 & 40 & 28 & 3.60 & .17 \\
\hline Whining & 37 & 17 & 14 & 7.36 & $.03 *$ \\
\hline Eyes closing & 7 & 10 & 22 & 4.65 & .10 \\
\hline Hitting & 12 & 13 & 6 & $-{ }^{\mathrm{a}}$ & .50 \\
\hline \multicolumn{6}{|l|}{ Choice making } \\
\hline Eye contact/gaze & 63 & 47 & 28 & 11.50 & $.00 * *$ \\
\hline Approaching person & 24 & 10 & 4 & 8.84 & $.01 *$ \\
\hline Reaching & 22 & 7 & 2 & $-{ }^{\mathrm{a}}$ & $.01 *$ \\
\hline Distancing from person & 17 & 7 & 4 & $-{ }^{\mathrm{a}}$ & .11 \\
\hline \multicolumn{6}{|l|}{ Answer } \\
\hline Laughing/smiling & 71 & 53 & 34 & 12.24 & $.00 * *$ \\
\hline Mouth closure & 20 & 30 & 6 & 8.23 & $.02 *$ \\
\hline Looking happy & 10 & 20 & 8 & $-^{\mathrm{a}}$ & .33 \\
\hline \multicolumn{6}{|l|}{ Imitation } \\
\hline Eye contact/gaze & 24 & 23 & 20 & 0.27 & .87 \\
\hline Words/speech & 12 & 10 & 8 & $-^{\mathrm{a}}$ & .93 \\
\hline
\end{tabular}

${ }^{\text {a }}$ As a result of low cell frequencies no chi-square value can be calculated. Fisher's exact test $p$-value is given

$* p<.05 ; * * p<.01$ 
and functions were more common in females without epilepsy than in those with epilepsy.

There were several significant differences in communicative forms/functions between age groups (see Table 4). For example, results suggest a linear trend across age groups in the percentage of females with Rett syndrome in terms of communicative forms for the purpose of attracting attention to self, requesting objects, and choice-making.

Overall, results of the exploratory comparative analyses revealed that several communicative forms and functions were significantly related to living environment, presence/absence of epilepsy, and age. That is, higher percentages of females who showed some forms/functions were found in those who lived at home, who had no epilepsy and who were relatively young.

\section{Discussion}

Communicative forms and functions were explored in a large sample of females with Rett syndrome. Respondents reported a wide variety of forms and functions in this group. By far most females used prelinguistic communicative behaviors of which eye contact/gazing was the most common form. Females with Rett syndrome only rarely use symbolic forms for communication. These results are largely in agreement with those of other studies in this area (see e.g. Cass et al. 2003).

Comparative analyses revealed that some prelinguistic forms and functions of communicative acts for females with Rett syndrome were related to living environment, presence/absence of epilepsy, and age. In general, it may be concluded that communicative forms and functions were more prevalent in females who lived at home, in those without epilepsy and in those that were relatively young. These results should however be viewed with caution as our study was mainly descriptive and there may be interaction effects between these variables that might explain differences between subsamples. Our finding that communicative abilities were related to age and epilepsy are not in agreement with results from the study by Cass et al. (2003). Furthermore, our finding that very few females used symbolic communication skills (e.g. words) is not in agreement with findings from a study by Lavas et al. (2006) who found that more than one third of their sample used some type of symbolic communication (e.g. communication aids such as picture boards). However, it appeared that in the Lavas et al.'s study participants did not use these aids for communicative purposes.

It appears that communicative forms and functions are more developed in females with Rett syndrome who live at home as compared to those who live in a residential facility (see Table 2). Similar findings were reported by Didden et al. (2009) who investigated communicative forms and functions using the IPCA in 79 individuals with Angelman syndrome. One reason for this outcome is that in home environments communicative behaviors (e.g. eye contact/gaze, approaching) are more often elicited and reinforced than in residential facilities. The level of adult attention is much higher in home settings than in residential facilities. Prelinguistic behaviors that are spontaneously used by females with Rett syndrome may be extinguished if these behaviors (forms) are not elicited and reinforced by caregivers in residential settings. 
It is suggested that intervention should focus on developing further the joint attention behaviors, intentional communications and communicative functions spontaneously used by individuals with disorders in the Rett syndrome complex (Dahlgren-Sandberg et al. 2000). Two intervention studies by Sigafoos and his colleagues (i.e., Sigafoos et al. 1995, 1996) in a case series showed that children with Rett syndrome may be taught to express choices via eye gazing and reaching and requesting via a "want" symbol. Results of these studies suggest that children with Rett syndrome may display intentional alternative communicative behaviors and that such behaviors may be taught using instructional procedures (see Duker et al. 2004; Sigafoos et al. 2009).

Several limitation of the study should be mentioned. A limitation of the present study is that we did not compare outcomes to those of one or more control groups thereby limiting the generality of our findings. Comparative studies in which a sample of individuals with Rett syndrome are included have been rarely conducted. For example, Matson et al. (2008a) compared communicative skills of a small group $(n=6)$ of adult females with Rett syndrome to adults with autism and controls. The groups were matched according to age, gender and level of intellectual disability. They found no significant differences between groups in communication abilities. A second limitation is that the validity of our conclusions is unknown. We do not know if the communicative behaviors are indeed communicative as mentioned by parents/ caregivers. Especially in individuals with Rett syndrome it is difficult to assess communicative forms and functions of (prelinguistic) behaviors (see e.g., DahlgrenSandberg et al. 2000). However, Sigafoos et al. (2000b) have shown that outcomes of the IPCA were in agreement with those of naturalistic observations in a small number of girls with Rett syndrome suggesting that communicative forms and functions may be identified in these individuals. Finally, due to the relatively small sample size, we were not able to analyse interaction effects. That is, associations between communicative forms/functions and other variables may be influenced by their interactions with 'third' variables.

Acknowledgements We thank the parents and caregivers of individuals with Rett syndrome for their participation.

Open Access This article is distributed under the terms of the Creative Commons Attribution Noncommercial License which permits any noncommercial use, distribution, and reproduction in any medium, provided the original author(s) and source are credited.

\section{References}

Budden, S., Meek, M., \& Henighan, C. (1990). Communication and oral-motor function in Rett syndrome. Developmental Medicine and Child Neurology, 32, 51-55.

Cass, H., Reilly, S., Owen, L., Wisbeach, A., Weekes, L., Slonims, V., et al. (2003). Findings from a multidisciplinary clinical case series of females with Rett syndrome. Developmental Medicine and Child Neurology, 45, 325-337.

Coleman, M., Brubaker, J., Hunter, K., \& Smith, G. (1988). Rett syndrome: a survey of North American patients. Journal of Mental Deficiency Research, 32, 117-124.

Dahlgren-Sandberg, A., Ehlers, S., Hagberg, B., \& Gillberg, C. (2000). The Rett syndrome complex: communication functions in relation to developmental level and autistic features. Autism, 4, $249-267$. 
Didden, R., Sigafoos, J., Korzilius, H., Baas, A., Lancioni, G., O’Reilly, M., et al. (2009). Form and function of communicative behaviours in individuals with Angelman syndrome. Journal of Applied Research in Intellectual Disabilities, 22, 526-537.

Duker, P., Didden, R., \& Sigafoos, J. (2004). One-to-one training: Instructional procedures for learners with developmental disabilities. Austin: Pro-Ed.

Hetzroni, O., \& Rubin, C. (2006). Identifying patterns of communicative behaviors in girls with Rett syndrome. Augmentative and Alternative Communication, 22, 48-61.

Keen, D., Woodyatt, G., \& Sigafoos, J. (2002). Verifying teacher perceptions of the potential communicative acts of children with autism. Communication Disorders Quarterly, 23, 133-142.

Laurvick, C., de Klerk, N., Bower, C., Christodoulo, J., Ravine, D., Ellaway, C., et al. (2006). Rett syndrome in Australia: a review of the epidemiology. Journal of Paediatrics, 148, 347-352.

Lavas, J., Slotte, A., Jochym-Nygren, M., Van Doorn, J., \& Witt-Engerstrom, I. (2006). Communication and eating proficiency in 125 females with Rett syndrome: the Swedish Rett Center survey. Disability \& Rehabilitation, 28, 1267-1279.

Matson, J., Dempsey, T., \& Wilkins, J. (2008a). Rett syndrome in adults with severe intellectual disability: exploration of behavioral characteristics. European Psychiatry, 23, 460-465.

Matson, J., Fodstad, J., \& Boisjoli, J. (2008b). Nosology and diagnosis of Rett syndrome. Research in Autism Spectrum Disorders, 2, 601-611.

Sigafoos, J., Laurie, S., \& Pennell, D. (1995). Preliminary assessment of choice making among children with Rett syndrome. Journal of the Association for Persons with Severe Handicaps, 20, 175-184.

Sigafoos, J., Laurie, S., \& Pennell, D. (1996). Teaching children with Rett syndrome to request preferred objects using aided communication: two preliminary studies. Augmentative and Alternative Communication, 12, 88-96.

Sigafoos, J., Woodyatt, G., Keen, D., Tait, K., Tucker, M., Roberts-Pennell, D., et al. (2000a). Identifying potential communicative acts in children with developmental and physical disabilities. Communication Disorders Quarterly, 21, 77-86.

Sigafoos, J., Woodyatt, G., Tucker, M., Roberts-Pennell, D., \& Pittendreigh, N. (2000b). Assessment of potential communicative acts in three individuals with Rett syndrome. Journal of Developmental and Physical Disabilities, 12, 203-216.

Sigafoos, J., Green, V., Schlosser, R., O’Reilly, M., Lancioni, G., Rispoli, M., et al. (2009). Communication intervention in Rett syndrome: a systematic review. Research in Autism Spectrum Disorder, 3, 304-318.

Smeets, E., Schollen, E., Moog, U., Matthijs, G., Herbergs, J., Smeets, H., et al. (2003). Rett syndrome in adolescents and adult females: clinical and molecular genetic findings. American Journal of Medical Genetics, 122 A, 227-233.

Tait, K., Sigafoos, J., Woodyatt, G., O’Reilly, M., \& Lancioni, G. (2004). Evaluating parent use of functional communication training to replace and enhance prelinguistic behaviors in six children with developmental and physical disabilities. Disability \& Rehabilitation, 26, 1241-1254.

Woodyatt, G., \& Ozanne, A. (1992). Communication abilities and Rett syndrome. Journal of Autism and Developmental Disorders, 22, 155-173. 